\title{
Educação sexual e sexualidade, intuição e sensibilidade: referências para práticas pedagógicas de professores na Educação Básica
}

\author{
Vera Márcia Marques Santos \\ Universidade do Estado de Santa Catarina (UDESC), Santa Catarina \\ veramarquessantos@gmail.com
}

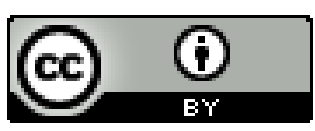

Educação: teoria e prática, Rio Claro, SP, Brasil - elSSN: 1981-8106

Está licenciada sob Licença Creative Common

\section{Resumo}

Este artigo é um recorte da pesquisa de doutoramento que estabeleceu diálogos sobre formação continuada e práticas pedagógicas de professores e professoras no Brasil e em Portugal, nos quais é recorrente o discurso de que "a intuição e a sensibilidade" referenciam práticas pedagógicas de professores/as no que se refere às manifestações da sexualidade em espaços escolares. $O$ discurso que deu origem à tese que motivou a referida pesquisa é proveniente da fala de professores e professoras de diferentes municípios de um Estado localizado no sul do Brasil, a partir dos espaços de formação inicial num curso de Pedagogia na modalidade a distância, no qual havia um corpo discente constituído por docentes que, na época, cursavam o ensino superior. Optouse pela pesquisa de cunho qualitativo, na qual se pode perceber que a sensibilidade e a intuição não substituem o conhecimento e a formação, mas podem ser elementos importantes para um fazer pedagógico cuidadoso no que se refere às questões que envolvem a sexualidade no processo educativo.

Palavras-chave: Educação sexual e sexualidade. Práticas pedagógicas. Intuição e sensibilidade. Formação de professores. Educação Básica.

\section{Sex education and sexuality, intuition and sensitivity: references to pedagogical practices of teachers in basic education.}

\begin{abstract}
This article is an excerpt from the systematization of doctoral research which established dialogues on continuing education, and pedagogical practices of teachers and teachers in Brazil and Portugal, where it presents speech applicant that "intuition and sensitivity" refer pedagogical practices of teachers / as regards the manifestations
\end{abstract}


of sexuality in school premises. The speech that gave rise to the theory that motivated the research comes from the speech of teachers and teachers from different districts of a state in southern Brazil, from the spaces of initial training in pedagogy courses in the distance mode, where it had a student body made up of teachers that the time attending higher education. We opted for qualitative research, where one can see that the sensitivity and intuition does not replace the knowledge and training, but can be important elements for making pedagogical careful regarding the issues surrounding sexuality in the educational process.

Keywords: Sex education and sexuality. Pedagogical practices. Intuition and sensitivity. Teacher training. Basic education.

\section{Educación sexual y sexualidad, intuición y sensibilidad:}

\section{referencias para las prácticas pedagógicas de profesores en la Educación Básica}

\section{Resumen}

Este artículo es un fragmento de la investigación de doctorado que estableció diálogos sobre la formación continua y prácticas pedagógicas de profesores y profesoras en Brasil y en Portugal, donde es recurrente el discurso de que "la intuición y la sensibilidad" hacen referencia a prácticas pedagógicas de profesores/as en lo que se refiere a las manifestaciones de la sexualidad en espacios escolares. El discurso que dio origen a la tesis, que motivó la mencionada investigación, proviene del habla de profesores y profesoras de diferentes municipios de un Estado localizado en el sur de Brasil, a partir de los espacios de formación inicial en un curso de Pedagogía en la modalidad a distancia, en que había un cuerpo discente constituido por docentes que, en la época, cursaban la enseñanza superior. Se optó por la investigación de cuño cualitativo, en la que se puede percibir que la sensibilidad y la intuición no sustituyen el conocimiento y la formación, sino que pueden ser elementos importantes para un hacer pedagógico cuidadoso en lo que se refiere a las cuestiones que envuelven la sexualidad en el proceso educativo.

Palabras clave: educación sexual y sexualidad. Prácticas pedagógicas. Intuición y sensibilidad. Formación de profesores. Educación Básica.

Esse texto é um recorte da sistematização da minha pesquisa de doutoramento na qual se travaram diálogos sobre formação continuada e práticas pedagógicas de professores e professoras no Brasil e em Portugal. A tese que motivou a referida pesquisa teve sua origem na fala de professoras e professores de diferentes municípios de um Estado no sul do Brasil, a partir dos espaços de formação inicial, na disciplina Educação e Sexualidade nos cursos de Pedagogia, na modalidade presencial e a distância (EaD). 
É importante destacar que, na Pedagogia EaD, havia um corpo discente constituído por docentes, ou seja, professores com o curso profissionalizante habilitação em magistério séries iniciais e/ou educação infantil que cursavam o ensino superior de acordo com as orientações da última Lei de Diretrizes e Base da Educação no Brasil.

Nesse grupo de discentes/docentes, era recorrente o discurso de que a sensibilidade e a intuição "constituíam" os componentes que subsidiavam suas práticas pedagógicas, referindo-se às manifestações da sexualidade em sala de aula, uma vez que, de acordo com as suas observações, "pouco ou nada vinha dos espaços de formação inicial e/ou continuada". Faziam tais afirmações em relação ao curso de magistério (Ensino Médio) e à formação continuada das redes municipais e estadual de educação da qual faziam parte.

Para a pesquisa que investigou a legitimidade da tese em questão, a opção foi pela pesquisa qualitativa, "sem cair na já 'superada' discussão da qualidade em detrimento da quantidade, sempre considerando as possibilidades de abrangência, amplitude e dinamismo frente à temática aqui proposta." (SANTOS, 2002, p. 41). A opção justifica-se por se acreditar, assim como Bogdan e Biklen, que os

investigadores qualitativos estabelecem estratégias e procedimentos que thes permitam tomar em consideração as experiências do ponto de vista do informador. $O$ processo de condução de investigação qualitativa reflete uma espécie de diálogo entre os investigadores e os respectivos sujeitos, dado estes não serem abordados por aqueles de uma forma neutra. (1994, p. 51).

Nas palavras de Denzin e Lincoln "a pesquisa qualitativa é, em si mesma, um campo de investigação" (2006, p. 16). Estes autores, na busca por uma definição para a pesquisa qualitativa, dialogam com Nelson et al., definindo que:

A pesquisa qualitativa é um campo interdisciplinar, transdisciplinar e, às vezes, contradisciplinar, que atravessa as humanidades, as ciências sociais e as ciências físicas. [...]. Ao mesmo tempo, trata-se de um campo inerentemente político e influenciado por múltiplas posturas éticas e políticas. (1992, p. 21). 
Isso remete ao fato de que não é possível pensar pesquisa ou pesquisador a partir da neutralidade, devido à complexidade e ao dinamismo que a envolvem. Para André (1999), a pesquisa qualitativa é o estudo do fenômeno em seu acontecer natural, não envolvendo manipulação de variáveis, nem tratamento experimental. Pressupõe uma visão holística dos fenômenos, englobando todas as interações entre os componentes de uma situação, os aspectos subjetivos do comportamento das pessoas, a relação com o cotidiano e a construção da realidade.

Ocorre a relativização da objetividade, pela não neutralidade do pesquisador, destacando-se a intersubjetividade, ao que “(...) podemos dizer que as pesquisas qualitativas têm se preocupado com o significado dos fenômenos e processos sociais, levando em consideração as motivações, crenças, valores, representações sociais que permeiam a rede de relações sociais." (PÁDUA, 1996, p. 31).

Parece, então, que a pesquisa, o pesquisador e os pesquisados só fazem sentido na medida em que participam da produção do conhecimento em questão e dele tomam posse. E, ainda mais, tal qual propõe Freire (1985), é preciso não perder de vista a indagação: "a quem sirvo com a minha ciência?". Esse teórico estabelece um desafio com esse questionamento que, para ele, é uma pergunta constante a ser feita por todos os pesquisadores. Esse contexto aponta, ainda, para a coerência com a opção feita por cada um, o que exprime também a coerência em nossas práticas. Coerência essa entendida como fonte de sentido e de significado conscientes. Para estar consciente de algo é preciso redescobrir a intencionalidade da relação sujeitomundo.

A consciência é intencional, ela não é pré-feita, pré-fabricada, não está pronta: “a pesquisa é sempre uma busca de saberes que reúne processos de simplificação e processos de complexificação acontecendo simultaneamente para a resolução de problemas e dúvidas a serem investigadas" (SILVA, 2001, p. 34), vislumbrando as possibilidades que esse compromisso impõe.

A abordagem qualitativa parte do fundamento de que há uma relação dinâmica entre o indivíduo e a sociedade, uma interdependência entre o sujeito e o objeto de estudo, um vínculo indissociável entre o mundo objetivo e a subjetividade da pessoa 
que participa, ampliando as possibilidades de interpretação e compreensão do cotidiano e disponibilizando meios para se apreender a complexidade humana.

Enfim, a necessidade de se utilizar a abordagem qualitativa na área da educação sexual justifica-se pelo fato de que é imprescindível a consciência de que esse tema não se limita a um fenômeno biológico, tal qual temos encontrado em muitos momentos, nos diferentes espaços educativos, mas que é constituído historicamente, de forma que, "[...] um conhecimento do conhecimento anterior (o que se dá ao nível da sua experiência quotidiana) se torna um novo conhecimento." (FREIRE, 1981, p. 35).

Esse novo conhecimento, que se estabeleceu a partir do diálogo entre pesquisadora, sujeitos, teoria e práticas pedagógicas, deu-se como já anunciado no cotidiano profissional, na escuta necessária à organização do conhecimento. Saber escutar é um dos saberes necessários à prática educativa (FREIRE, 1997), ao que Saul acrescenta: "trata-se de uma escuta que vai além da capacidade auditiva e difere da pura cordialidade." (2008, p. 171). Desse modo, a escuta e os diálogos subsidiaram metodologicamente esta pesquisa.

Essa escuta das professoras ${ }^{1}$ despertou a atenção para os discursos recorrentes de que os conteúdos que têm respaldado práticas pedagógicas no que se refere à sexualidade no contexto escolar, bem como o lugar de busca de conteúdo(s) que pudessem respaldar as suas práticas, em suas percepções, se sustentam na sensibilidade e na intuição de cada uma e bem pouco ou nada é decorrente de seus processos de formação.

Diante do que se coloca e tendo presente a herança positivista no universo acadêmico, foram feitos estudos dos conceitos de sensibilidade e intuição, não antes, porém, de ter feito muitos questionamentos em vários momentos sobre a originalidade e validade da tese que moveu a pesquisa já mencionada. No entanto, nos

\footnotetext{
1 Diferente do que convencionalmente acontece na prática da escrita acadêmica, na qual, habitualmente, utiliza-se o masculino como norma ao referir-se ao gênero masculino e feminino, uso neste artigo, assim como o fiz em minha tese de doutoramento, o termo professora, no feminino. Por haver, no contexto da pesquisa, mais professoras do que professores, ou seja, por elas representarem a maioria, considerei que aquela prática contribui para a ressignificação de práticas de perpetuação da cultura machista na lida com os papéis sexuais.
} 
momentos de dúvida, sempre ocorria a ideia de que se, para a pesquisadora/professora formadora, não era uma situação tranquila, como não deveriam se sentir as demais professoras integrantes da pesquisa diante da tomada de decisões do que fazer em relação às manifestações da sexualidade cotidianas de alunas/os? Agir a partir da sensibilidade e intuição talvez fosse uma espécie de estar "à deriva", quando se trata dos saberes que têm sustentado as suas práticas pedagógicas envolvendo a sexualidade, conforme se observa no depoimento que segue:

Fazemos aquilo que nos parece mais sensato para o momento, o que nem sempre é o melhor ou o correto, podemos deixar marcas boas ou ruins, o fato é que na maioria das vezes agimos com a intuição por não saber qual a maneira cientifica de lidar com estas situações todas. (Depoimento registrado em aula, de aluna/docente em uma turma no Norte do Estado de Santa Catarina, em 2006).

A intuição a que se refere essa professora, assim como se referiram outras, leva-nos a pensar muito sobre a questão, gerando uma inquietação latente e, muitas vezes, a angústia de considerar não ser possível realizar uma pesquisa acadêmica consistente se ela estiver sustentada em pilares como a sensibilidade e a intuição. Entretanto, buscou-se parceiros(as) teóricos(as) que pudessem contribuir com o compromisso assumido com o grupo de professoras/discentes.

Observaram-se, logo no início, as dificuldades que deveriam ser enfrentadas, o que gerou uma sensação de solidão política e teórica para o percurso de compreensão daquele discurso envolvendo a sensibilidade e a intuição. Logo, uma certeza concretizou-se: não seria possível declinar. Isso em respeito às professoras que, de certa forma, esperavam da formadora/pesquisadora a tarefa de discutir, sistematizar e publicizar suas necessidades, angústias e medos em relação aos saberes de suas práticas pedagógicas no processo de educação sexual em que estavam inseridas.

Nesse contexto, fez-se necessária a compreensão do significado dos conceitos sensibilidade e intuição, busca essa realizada com base em referências como Japiassú e Marcondes (1996); Bazarian (1986); Maturana (2002) e Silva (2009). 
A busca da compreensão de tais conceitos, assim como os relatos do grupo discente, evocou lembranças das práticas e vivências pedagógicas e de formação desta pesquisadora, principalmente, em formação continuada, sobre a atuação na educação infantil e nos anos iniciais do Ensino Fundamental, nos quais, muitas vezes, também ela ficava desconcertada sem saber a quem recorrer e como fazer em situações semelhantes às registradas por essas professoras, como por exemplo, numa situação em um menino, na educação infantil, manipulava seus órgãos genitais em sala de aula.

Registra-se que, muitas vezes, as intervenções desta pesquisadora ocorriam da mesma forma a que se referiram as professoras quando remetem à sensibilidade e intuição, situações essas que a levaram a buscar respostas e fundamentação teórica também a partir do seu processo formativo.

Tudo isso fez com que aumentasse a cumplicidade e a responsabilidade com o grupo de professoras que deu origem à tese em questão, proporcionando a percepção de que aquele era um momento ímpar na sua trajetória como professora formadora e, principalmente, como pesquisadora. Tal contexto exigiu e releitura de Carlos Rodrigues Brandão, quando se refere à forma como se relacionam o pesquisador, os pesquisados/sujeitos e o objeto da pesquisa, proporcionando-me perceber o que seja:

Ter no agente que pesquisa uma espécie de gente que serve. Uma gente aliada, armada dos conhecimentos científicos que foram negados ao povo, (...) - onde afinal pesquisadores-e-pesquisados são sujeitos de um mesmo trabalho comum, ainda que em situações e tarefas diferentes. (1985, p. 11).

A partir daquele momento ficou claro o quanto essa tese poderia ser significativa para essas professoras, bem como para outros grupos no que se refere aos saberes de suas práticas pedagógicas, revelados no fazer cotidiano ou mesmo em processos de formação contínuo.

Foi percebido que algumas indagações reiteradas no decorrer da trajetória e das práticas pedagógicas desta pesquisadora, trajetória esta envolvida com a formação inicial e continuada de muitos(as) professores e professoras, eram indagações também 
desses/as profissionais, questionamentos esses que se tornaram parte fundante da pesquisa em questão, como pode ser observado a seguir:

- O conteúdo do processo de formação pode mudar posturas sobre os saberes pedagógicos das práticas de professoras(es) educadoras(es) sexuais ${ }^{2}$ ?

- Até que ponto e de que forma um processo de formação que envolva temas/conteúdos voltados para educação sexual pode contribuir com os saberes das práticas pedagógicas de professores e professoras(es) educadores(as) sexuais?

- Quais elementos podem ser essenciais para que este(a) educador(a) sexual possa entender-se como fundamental num processo de mudança de paradigmas?

$\mathrm{Na}$ busca por respostas para esses e tantos outros questionamentos, faz-se necessário refletir sobre o conceito de paradigma encontrado em Melo e Pocovi no diálogo de Nadir Azibeiro com Edgar Morin,

Chamamos paradigmas às estruturas de pensamento que, de modo quase que inconsciente, comandam nosso modo de ser, de olhar, de viver, de fazer, de falar sobre as coisas e sobre nós mesmos. São os nossos sistemas mentais, que filtram toda a informação que recebemos: ignoramos, censuramos, rejeitamos, desintegramos o que não queremos saber. Não os entendemos como modelos, rígidos e acabados, mas como horizontes, que se ampliam e se modificam a cada passo dado, ou teias de significados, sempre se re-tecendo e re-articulando. (2002, p. 29).

Diante dessa constatação, fez-se necessário re-tecer as malhas da história que têm sustentado nossas práticas pedagógicas, na perspectiva de que isso pudesse ajudar a romper com práticas que ficam somente no senso comum e, por isso mesmo, continuam sendo repressoras e/ou preconceituosas.

\footnotetext{
${ }^{2}$ Cabe observar que o termo educador sexual se justifica dado o fato de que somos sempre educadores sexuais, independentemente da área em que atuamos, considerando os processos interativos a que estamos submetidos o tempo todo.
} 
Isso permitiu refletir sobre as questões pedagógicas envolvendo a sexualidade que atraíram a pesquisadora desde cedo, talvez pelas dificuldades que teve com as temáticas relativas à infância e à adolescência, e, posteriormente, o que mais presente se faz, a profissional na educação, uma profissional sempre envolvida com a paixão que move os seres humanos em suas lutas e lidas do cotidiano. A paixão que sempre nutri pela educação não relega o ato de educar a uma atitude missionária; essa paixão sempre esteve ligada ao belo, ao estético e à alteridade, a algo que comove, que mexe com o ser humano, em contato com muitos outros seres humanos que merecem ser tratados como tais.

Com isso, destaca-se um dos dilemas da educação: deixar de lado o "ser humano". Para isso, precisa-se de uma humana docência, ou de docentes mais humanos, com práticas mais humanizadas, nas quais o rigor da racionalidade não venha a sobrepujar a beleza e a potencialidade que podem emergir da emoção, da sensibilidade e da intuição. Não a intuição como característica de pessoas inexperientes, mas a intuição que "[...] pressupõe sim uma gama de conhecimentos e experiências adquiridas ao longo da trajetória de vida." (SILVA, 2009, p. 73).

De acordo com Japiassú e Marcondes (1996). fazer o que é mais sensato para o momento significa buscar apoio junto ao empírico, beber na fonte do conhecimento imediato da experiência.

Essa percepção advinda do que seja a intuição, ao ser trabalhada racionalmente, poderá vir a ser conjectura ou hipótese, e nesse caso, arrisca-se afirmar, com respaldo nas falas oriundas dos diferentes grupos em processo de formação continuada, que o conhecimento utilizado por professoras e professores educadores sexuais muito pouco tem vindo das instituições formadoras, mas sim do bom senso (ou não) e vontade de acertar. Como afirma Paulo Freire:

Nenhuma formação docente verdadeira pode fazer-se alheada, de um lado, do exercício da criticidade que implica a promoção da curiosidade ingênua à curiosidade epistemológica, e de outro, sem o reconhecimento do valor das emoções, da sensibilidade, da afetividade, da intuição ou adivinhação. Conhecer não é, de fato, adivinhar, mas tem algo que ver, de vez em quando, com 
adivinhar, com intuir. O importante, não resta dúvida, é não pararmos satisfeitos ao nível das intuições, mas submetê-las à analise metodicamente rigorosa de nossa curiosidade epistemológica. (1996, p. 45).

E, assim, as professoras e os professores consigam, por certo, a superação da condição inicial da sensibilidade e intuição em suas trajetórias profissionais, considerando-se, como Silva, que "a intuição, ao contrário do que alguns pensam, não é uma característica de pessoas inexperientes, ela pressupõe sim uma gama de conhecimentos e experiências adquiridas ao longo da trajetória de vida" (2009, p. 73), sendo utilizadas sempre que necessário em suas práticas educativas.

Ao pensar as práticas pedagógicas, nesse contexto de superações, foram buscados fundamentos também em Freire (1978), quando ele diz que a prática educativa corresponde a uma concepção dos seres humanos e do mundo, o que exige uma postura teórica por parte do educador; toda prática social, nas palavras deste autor, pressupõe ou resulta de um referencial de valores e de concepção de mundo. 0 autor chama a atenção para as implicações decorrentes das crenças e valores, que determinam a ação do ser humano, ressaltando a necessidade e a importância da percepção crítica da realidade, com vistas a uma ação transformadora.

Com isso, retoma-se nessa dimensão a origem desta tese: a sensibilidade e intuição como elementos forjadores de saberes nas práticas pedagógicas de professoras. Para melhor compreender o significado do que elas traziam em suas falas, ou seja, o que seriam essas "tais" sensibilidade e intuição, recorremos novamente a Japiassú e Marcondes, que, em relação ao termo sensibilidade, apontam ser, em sentido genérico, a "capacidade de sentir, de ser afetado por algo, de receber através dos sentidos impressões causadas por objetos externos." (1996, p. 245). Esses filósofos, dialogando com Kant, observam:

Kant usa esse termo (Sinnlichkeit) para designar a receptividade da consciência, a capacidade de formarmos objetos graças à maneira pela qual estes nos afetam. A sensibilidade nos fornece assim a matéria dos fenômenos. Kant considera o 
espaço e o tempo como formas puras da sensibilidade, ou seja, condições de possibilidade de termos impressões sensíveis. (1996, p. 245).

Bazarian (1986) mostra que a palavra intuição vem do latim in tueri, e quer dizer ver em, contemplar, o que para ele significa um conhecimento direto, imediato do conjunto de qualidades sensíveis e essenciais dos objetos e de suas relações, sem uso do raciocínio discursivo, sem o uso da razão. É importante perceber que essa definição de intuição pressupõe algo que está além da razão, e não aquém dela. Pode se tornar, por exemplo, uma importante ferramenta para cientistas e pesquisadores, sendo considerada, por alguns, parte intrínseca do próprio método científico.

Japiassú e Marcondes consideram a intuição como um "sentimento súbito (insight) de um caminho para a solução de um problema ou da descoberta de uma relação científica." (1996, p. 147). De acordo com essa premissa, parece que, quando surge o termo intuição nos contextos de formação de professoras e educação sexual, ele vem exatamente ao encontro do que aqui apontam Japiassú e Marcondes, ou seja, para a solução das questões referentes à sexualidade que aparecem em suas práticas pedagógicas. Essas professoras, inicialmente, têm se valido desse insight para tratar de questões para as quais, de acordo com suas falas, "não estão, ou não se sentem preparadas".

Silva discute a "intuição como uma forma de saber/fazer" e explicita ser muito difícil expressar uma conceitualização de forma escrita.

Entendo a intuição como uma forma de conhecer, de ser e fazer sensível, uma forma de saber próprio do ser humano que parece ter sido esquecida, ao longo do tempo. [...] para expressar melhor a ideia de intuição que busco, uso a expressão saber/fazer, pois ela conota não só uma forma de conhecimento, mas também a questão da ação, do movimento, que é fundamental à intuição. (2009, p. 60).

Esse pesquisador deixa claro que, com essa ideia, não está defendendo que o tema intuição "seja a alternativa a todos os problemas no campo da educação, mas sim que essa é uma questão pouco explorada por diferentes motivos." (2009, p. 62). 
Pontua que entre esses motivos estão em geral "a relação que é feita entre o tema da intuição e formas mágicas ou místicas de interpretar o mundo e a supervalorização, na sociedade contemporânea, do pensamento racional" (2009, p. 62).

A intuição encontra-se invariavelmente no campo subjetivo e individual. Não acontece da mesma maneira de pessoa para pessoa, ela é fluida e momentânea, não se pode definir precisamente quando ela acontece, o que faz com que ela aconteça ou, pelo menos, se tem muita dificuldade de reconhecer quando ela se dá. Essa parece ser mais uma das dificuldades de pensar sobre essa temática, já que ela se encontra no campo da consciência humana, algo que a filosofia e a ciência moderna têm tentado entender unicamente em termos das funções do cérebro. (SILVA, 2009, p. 64).

A intuição, ao se configurar como um dos eixos e uma das questões mobilizadoras desta tese, torna-se também a possibilidade de poder explicitar a dualidade histórica entre emoção e razão. Sobre essa intuição eivada da emoção que move o ser humano, encontramos considerações importantes em Maturana:

Vivemos uma cultura que desvaloriza as emoções em função de uma supervalorização da razão, num desejo de dizer que nós, os humanos, nos distinguimos dos outros animais por sermos seres racionais. Mas acontece que somos mamíferos e, como tais, somos animais que vivem na emoção. As emoções não são algo que obscurece o entendimento, não são restrições da razão: as emoções são dinâmicas corporais que especificam os domínios de ação em que nos movemos. Uma mudança emocional implica uma mudança de domínio de ação. Nada nos ocorre, nada fazemos que não esteja definido como uma ação de certo tipo por uma emoção que a torna possível. (2002, p. 92).

Pode-se afirmar assim, que, quando as professoras explicitam que suas práticas pedagógicas se "fundamentam" na intuição, estão se referindo também a essas emoções e a suas implicações na ação que, num determinado momento, elas têm que assumir. 
Em diálogo com Atkinson, Claxton e Eraut (2002), Silva observou que a intuição é "[...] a apreensão imediata de uma situação ou realidade, 'sem nenhum tipo de racionalização' que 'resulta em uma reflexão, um sentimento, impressão ou sensação que pode vir seguida de uma decisão ou ação." (2009, p. 69).

Com isso, concordamos com Silva quando assinala que aceitar a intuição docente não significa reduzir a sua competência ou uma relação de negação do saber desse profissional, mas significa evidenciar, "de forma didática, a necessidade de problematizar de onde provêm essas respostas dinâmicas tomadas sem um processo reflexivo mais demorado e como a formação [continuada] utiliza-se, ou não, dessas experiências." (2009, p. 67).

Ao serem questionadas sobre o que pensam, como organizam as ideias para mais um momento de intervenção pedagógica sobre a temática, uma professora expressou-se nos seguintes termos:

Acho que é mais na intuição, como se a gente recebesse uma espécie de luz que vem para ajudar naquele momento que é tão difícil. Porque você fica chocada com a situação e tem que contornar, tem que conversar mostrar como é, e tem que ser ali, na hora, então seja o que deus quiser e, a gente faz o que parece mais certo para aquele momento, acho que é isso mesmo na base da intuição, sem muito tempo para pensar, para organizar o pensamento. (Profa $\mathrm{C}$ )

Nesse contexto, não se pode deixar de enfatizar o que declararam essas professoras, quando se referiram ao fato de que "muito pouco tem vindo das instituições formadoras", por considerar ser essa também uma forma de publicizar o que se ouve por entre as paredes de salas de aula ou de auditórios de formação continuada, por duas razões:

1 - São, ainda, muito poucas as instituições de formação inicial e/ou continuada que têm possibilitado a contemplação da temática em seus projetos pedagógicos;

2 - Mesmo quando o/a professor(a) traz em seu currículo acadêmico ou profissional a temática acessada de forma institucionalizada (seja através de 
sua formação inicial ou continua/continuada), na ampla maioria das vezes, parece não conseguir transpor o arcabouço teórico conceitual para as situações pedagógicas que envolvem a sexualidade, pois não se sente seguro, como se pode perceber, respectivamente, no relato de duas professoras:

Eu também quero aprender, realmente tem coisas que a gente não sabe o que fazer, tanto é que sempre peço socorro às gurias [professoras colegas de trabalho], que também o tempo todo pedem socorro. Realmente, quando a gente se depara com a situação não quer amedrontar a criança e de alguma forma acaba amedrontando, porque não sabe o que fazer. (Profa A)

Temos hoje que trabalhar a sexualidade sem um suporte e eu acho que é complicado entrar em uma sala de aula e trabalhar sexualidade assim, na coragem, ou a gente faz na base da intuição, ainda assim se consegue trabalhar com os alunos muito melhor do que trabalhar em casa. [...] Mas porque na minha formação (pausa), minha mãe sentava no sofá e dizia olha só L., sabe aquele negócio, aquela coisa, que até então eu tinha que achar qual era a coisa, aquela coisa, aquele negócio [genitais]. Como é que hoje eu vou chamar o meu filho e dizer vem cá, vamos conversar, é difícil, porque eu já tenho isto. Mas mesmo assim com os alunos é mais tranquilo. Apesar de que quando trabalhei com uma 4a série foi um trabalho, porque quando passou para os órgãos, ai meu deus! (risos) era um buchicho só, era difícil desviar a atenção das piadinhas, dos risos. Meu deus do céu essa 4ạ série pra mim também não foi nada fácil, agora com os menores eu trabalho melhor. (Profa B)

Quando essas professoras, em seus relatos, se reportam às manifestações da sexualidade por parte de seus alunos e alunas em seus espaços de práticas pedagógicas, as decisões que têm que tomar diante de tais situações, bem como os dramas e dilemas em que se veem, as aproximam do que Tardif apresenta ao se referir a estudos feitos sobre o saber dos professores, que "[...] depende, por um lado, das condições concretas nas quais o trabalho deles se realiza e, por outro, da personalidade e da experiência profissional dos próprios professores" (2007, p16), 
podendo ser a sensibilidade e a intuição motivadores deste profissional para o seu processo de formação continuada, percebendo-se como sujeito pesquisador de e na sua prática pedagógica.

\section{Ao finalizar: algumas considerações}

$\mathrm{Na}$ fala das professoras que participaram da pesquisa, assim como nos(as) teóricos(as) em que se buscou parceria e cumplicidade para essa tarefa de sistematização, percebe-se, a partir da escuta atenta de quem ao escutar "dialoga com", que os saberes que têm referenciado as práticas pedagógicas de professores e professoras têm sido a sua própria sensibilidade e intuição para situações que envolvem a sexualidade e muito pouco tem vindo das instituições formadoras, embora a formação continuada se apresente como uma potente alternativa possibilitadora de qualificação da prática docente. Sustenta-se, pelo menos parcialmente, que, de fato, a sensibilidade e a intuição são marcas centrais das interlocutoras e revelam, antes de tudo, a preocupação de profissionais conscientes de sua responsabilidade social, bem como as implicações que perpassam suas práticas pedagógicas.

Com isso, concorda-se com Silva quando observa que "a intuição, ao contrário do que alguns pensam, não é uma característica de pessoas inexperientes, ela supõe sim um gama de conhecimentos e experiências adquiridas ao longo da trajetória da vida." (2009, p. 73).

No entanto, "a intuição, nessa perspectiva, não substitui o conhecimento e a formação em determinados saberes" (ibid.). Ao contrário disso, percebeu-se que essa intuição pode funcionar como uma forma de superação, por parte das professoras, de obstáculos e barreiras encontradas no momento em que elas têm de fazer uma intervenção pedagógica e se deparam com o conhecimento intuitivo.

Ainda mais, a sensibilidade e intuição aqui referidas são aquelas que deram origem a esse momento da trajetória acadêmica da pesquisadora, um momento em que é necessária uma resposta imediata àquela situação adversa na qual a única saída é "aplicar conhecimentos tácitos que se possam ter sobre determinada situação." (SILVA, 2009, p. 75). Concorda-se, ainda, com esse pesquisador quando ele observa que, se entendida dessa maneira, a intuição tem uma importante contribuição para as 
práticas pedagógicas, acrescentando-se aos saberes docentes e, consequentemente, ao processo de formação continuada de professores e professoras.

\section{Referências}

ANDRÉ, Marli Eliza D. A. Etnografia da prática escolar. 3. ed. Campinas: Papirus, 1999.

ATKINSON, Terry; CLAXTON, Guy (Org.). El professor intuitivo. Barcelona: Ediciones Octaedro, 2002. (Coleción Repensar la Educación, n.15)

BAZARIAN, Jacob. "Intuição Heurística: Uma Análise Científica da Intuição Criadora". 3. ed. São Paulo: Ed. Alfa- Omega, 1986.

BOGDAN, R.; BIKLEN, S. Investigação qualitativa em educação: uma introdução à teoria e aos métodos. Portugal: Porto Editora, 1994. (Coleção Ciências da Educação).

BRANDÃO, Carlos Rodrigues. Pesquisa participante. 5. ed. São Paulo: Editora Brasiliense, 1985.

DENZIN, Norman K. e LINCLN, Yvonna S. O planejamento da pesquisa qualitativa: teorias e abordagens. 2. ed. Porto Alegre: Artmed, 2006.

ERAUT, Michel. El professor intuitivo: una visión crítica. In: ATKINSON, Terry; CLAXTON, Guy (Org.). El professor intuitivo. Barcelona: Ediciones Octaedro, 2002. (Coleción Repensar la Educación, n.15).

FREIRE, Paulo. Criando métodos de pesquisa alternativa: aprendendo a fazê-la melhor através da ação. In: BRANDÃO, Carlos Rodrigues (Org.). Pesquisa participante. 5. ed. São Paulo: Brasiliense, 1985.

Educação: o sonho possível. In: BRANDÃO, Carlos Rodrigues (Org.). 0 educador: vida e morte: escritos sobre uma espécie em perigo. Rio de Janeiro: Graal, 1981. 1978.

A ação cultural para a liberdade e outros escritos. Rio de Janeiro: Paz e Terra,

Pedagogia da autonomia: saberes necessários à prática educativa. São Paulo: Paz e Terra, 1996.

Política e educação: ensaios. São Paulo: Cortez, 1997. (Coleção Questões da Nossa Época; 23). 
JAPIASSÚ, Hilton; MARCONDES, Danilo. Dicionário básico de filosofia. 3. ed. Rio de Janeiro: Jorge Zahar, 1996.

MATURANA, Humberto. Emoções e linguagem na educação e na política. 3a reimpressão. Tradução de José Fernando Campos Fortes. Belo Horizonte: Editora UFMG, 2002.

MELO, Sônia M. M. de e POCOVI, Rosi M. de Souza. Caderno pedagógico: educação e sexualidade. Florianópolis: UDESC, 2002.

PÁDUA, Elisabete M. M. de. Metodologia da pesquisa: abordagem teórico-prática. Campinas: Papirus, 1996.

SANTA CATARINA. Proposta Curricular de Santa Catarina. Educação Infantil. Ensino Fundamental e Médio. Temas Multidisciplinares. Florianópolis: SED/COGEN, 1998.

SANTOS, Vera Márcia Marques. A formação do educador frente à violência e o abuso sexual contra crianças e adolescentes. 2002. Dissertação (Mestrado). Florianópolis: FAED/UDESC, 2002.

SAUL, Ana Maria. Escutar. In: STRECK, Danilo R.; REDIN, Euclides e ZITKOSKI, Jaime José, (Orgs.). Dicionário Paulo Freire. Belo Horizonte: Autêntica Editora, 2008.

SILVA, Marcelo Silva da. "Alice vai à universidade!": docentes e docência universitária: trajetórias, saberes e intuições na formação da profissionalidade. 2009. Tese (Doutorado) - Universidade do Vale do Rio dos Sinos. São Leopoldo, 2009.

SILVA, Edna Aparecida da. Filosofia, educação e educação sexual: matrizes filosóficas e determinações pedagógicas do pensamento de Freud, Reich e Foucault para a abordagem educacional da sexualidade humana. 2001. Tese (Doutorado) Universidade Estadual de Campinas. Campinas, 2001.

TARDIF, Maurice. Saberes docentes e formação profissional. 8. ed. Petrópolis: Vozes, 2007.

Enviado em Abril/2013

Aprovado em Outubro/2013 